\title{
The outcome of low-frequency intravitreal bevacizumab therapy for macular edema in retinal vein occlusions
}

This article was published in the following Dove Press journal:

Clinical Ophthalmology

21 June 2017

Number of times this article has been viewed

Biljana Ivanovska Adjievska'

Salih Boskurt ${ }^{\prime}$

Nikola Orovcanec ${ }^{2}$

Vesna Dimovska-Jordanova ${ }^{3}$

'Department for Posterior Segment, European Eye Hospital, Skopje, Republic of Macedonia; ${ }^{2}$ Department for Medical Statistics, Institute for Epidemiology and Medical Statistics, Medical Faculty, Skopje, Republic of Macedonia; ${ }^{3}$ Department for Retinal Diseases, University Clinic for Eyes Diseases, St Cyril and Methodius University, Skopje, Republic of Macedonia
Correspondence: Biljana Ivanovska Adjievska

European Eye Hospital, Sremski Front I, Skopje, Republic of Macedonia

Tel +38922050999

Fax +3892 2034989

Email ivanovska.biljana@gmail.com
Aim: We aimed to evaluate the 1-year efficacy and safety of low-frequency intravitreal bevacizumab in the treatment of macular edema due to retinal vein occlusions (RVOs).

Methods: The study comprised an interventional prospective study of patients with macular edema due to central retinal vein occlusion (CRVO) or branch retinal vein occlusion, followed for 12 months. Treatment-naïve patients with reduced best-corrected visual acuity (BCVA) and central macular thickness (CMT) of at least $250 \mu \mathrm{m}$ received intravitreal injection of bevacizumab. After 1 month, BCVA and optical coherence tomography (OCT) images of the macula were recorded. In patients with $<30 \%$ improvement in BCVA and CMT, two more injections were applied at 1.5-month intervals. In all other patients, further injections were applied as needed. In cases with ischemic areas of retina, laser photocoagulation of the retina was performed.

Results: In total, 33 patients with CRVO and 55 with BRVO were treated. After 1 year, 65 eyes (73.86\%) had clinically significant improvement of BCVA $(>0.3 \log$ of the minimum angle of resolution [logMAR] units) with average number of injections of 1.98. Improvement of mean BCVA in CRVO was significant $(P=0.001)$ from baseline $(1.2 \pm 0.95 \operatorname{logMAR}$ units) to 1 year $(0.75 \pm 0.6 \log$ MAR units). Significant improvement of mean BCVA $(P<0.001)$ was also found in BRVO, from $0.71 \pm 0.75 \log$ MAR units at baseline to $0.28 \pm 0.5 \log$ MAR units at 1 year. Baseline CMT was $852.21 \pm 298.20 \mu \mathrm{m}$ for CRVO and 597.95 $\pm 185.63 \mu \mathrm{m}$ for BRVO. In both groups, there was significant decrease $(P<0.001)$ in CMT after 1 year of treatment. Panretinal laser photocoagulation was done in $75.8 \%$ of all eyes with CRVO and sectoral photocoagulation in $49.1 \%$ of eyes with BRVO.

Conclusion: In macular edema due to RVO, intravitreal bevacizumab provides improvement in visual acuity and reduction of macular edema in a high percentage of treated eyes after 1 year, even with low number of injections.

Keywords: macular edema, retinal vein occlusion, bevacizumab, intravitreal injection

\section{Background}

Retinal vein occlusion (RVO) is the most common retinal vascular disease, after diabetic retinopathy. ${ }^{1}$ Epidemiological studies have shown that RVO prevalence varies from $0.3 \%{ }^{2}$ to $1.6 \%^{3}$ and that the primary risk factors are age, hypertension and coexisting cardiovascular disease..$^{2-6}$ Macular edema (ME) that occurs as a result of central retinal vein occlusion (CRVO) or branch retinal vein occlusion (BRVO) leads to loss of vision in up to $5 \%-15 \%$ of BRVO cases and in almost all cases of CRVO. ${ }^{7}$ Between the two presentations, branch occlusion is significantly more frequent and is responsible for $\sim 80 \%$ of $\mathrm{RVO}$. 
Historically, the most common recommendation in patients with BRVO was observation, although several larger studies have confirmed the effectiveness of laser photocoagulation (LPC) in the moderate improvement of visual acuity (VA) in BRVO and maintenance of VA in CRVO.${ }^{8,9}$ Moreover, intravitreal corticosteroids were used in the treatment of ME in RVO with varying success. ${ }^{10,11}$ Both treatments show significant but limited success.

In recent years, as vascular endothelial growth factor (VEGF) was found to be the primary cause for ME, ${ }^{12,13}$ multiple studies that investigated the effects of several anti-VEGF agents in the treatment of ME in RVO were conducted. ${ }^{14-16}$

In our study, we evaluated the effects of intravitreal bevacizumab on VA and anatomic results during the treatment of ME due to RVO, as well as its safety profile, over a period of 1 year. In orderto reduce the financial and logistical burden of the injections, we used one injection and pro re nata (PRN) regimen.

\section{Materials and methods}

Our interventional, nonrandomized, prospective study included patients with ME due to RVO (central or branch), treated and followed for 12 months. It was conducted in a tertiary eye clinic, the European Eye Hospital in Skopje, Republic of Macedonia, in the period 2013-2016. Thus, 105 patients were initially included, out of whom, 17 (16\%) dropped out due to failure to show up for all control tests up to 1 year, while 88 patients completed the study. The study included patients who had reduction of VA in the last 6 months of the evolution of the disease and in which optical coherence tomography (OCT) showed thickness of subcentral macular area of at least $250 \mu \mathrm{m}$. The study excluded patients with ME due to other causes (eg, diabetic retinopathy), patients with a significant degree of clouding of optical media (eg, cataract), patients who underwent some other surgeries of the eye in the past 6 months and patients who had previously been treated for RVO with LPC or intravitreal injections.

The first examination included collection of data about the duration of occlusion, previous eye diseases (interventions), existence of other systemic diseases, such as cardiovascular diseases, systemic hypertension, diabetes, thrombosis and so on. The ophthalmic examination included determination of best-corrected visual acuity (BCVA) in Snellen decimal units (converted to log of the minimum angle of resolution [logMAR] units), intraocular pressure (IOP), anterior and posterior segment examination with indirect ophthalmoscopy, description of the type of occlusion (CRVO or BRVO) and the findings of the fundus. The diagnosis was confirmed by fundus fluorescein angiography (FFA) and OCT of the macula (Topcon 3D OCT-2000), whereby the central macular thickness (CMT) was measured in microns. In addition, before the first injection, the following parameters of the general status were determined: differential blood count (platelets), lipid status, blood glucose and blood pressure.

Patients were administered intravitreal injection of $1.25 \mathrm{mg} / 0.05 \mathrm{~mL}$ bevacizumab (Avastin ${ }^{\circledR}$; Genentech Inc, San Francisco, CA, USA). After 1 week postinjection, the BCVA, the intraocular pressure (IOP) status and the existence of signs of infection were recorded. During the control examination after 1 month, BCVA and CMT (OCT image of macula) were compared to the preoperative results. In patients who had improvement in VA and decrease in central foveal thickness of at least $30 \%$ after the first injection, further injections were applied depending on anatomical and functional results, at the discretion of the treating physician. In patients who had improvement in VA and decrease in central foveal thickness of $<30 \%$, two more intravitreal injections of bevacizumab were applied at 1.5 -month intervals. In all patients with ischemic areas of the retina confirmed by FFA, LPC of the peripheral retina was done after the initial intravitreal treatment. At 3 months, 6 months and 1 year, the BCVA, IOP and CMT were documented for the controls.

This study was approved by the ethics committee of the Medical Faculty, University of Skopje, Republic of Macedonia. The study was conducted in accordance with the Declaration of Helsinki. All patients were informed about the use of bevacizumab off label and they provided informed consent to the intervention.

\section{Results}

In total, 88 eyes of 88 patients with ME due to RVO were treated. Mean age of the patients was $59.82 \pm 11.05$ (28-88) years; $43(48.86 \%)$ of these were female and 45 $(51.14 \%)$ were male. The average duration of the disease was 3.06 and 3.80 months for CRVO and BRVO, respectively. Accordingly, 51 patients were treated with a single intravitreal injection, 21 eyes received two injections and 16 eyes received $\geq 3$ injections. The average number of injections was 1.98 per eye in the 12-month period (Table 1).

Table I Demographic and baseline characteristics

\begin{tabular}{lll}
\hline Characteristics & CRVO $(\mathbf{n}=\mathbf{3 3})$ & BRVO $(\mathbf{n}=\mathbf{5 5})$ \\
\hline Mean age, years (SD, range) & $63(13.2,28-88)$ & $58(9.18,40-83)$ \\
Gender, male/female & $18 / 15$ & $27 / 28$ \\
Duration of disease, months (SD) & $3.06(4.76)$ & $3.80(6.29)$ \\
Number of injections, I:2: $\geq 3$ & $13: 9: 8$ & $38: 13: 8$ \\
\hline
\end{tabular}

Abbreviations: BRVO, branch retinal vein occlusion; CRVO, central retinal vein occlusion. 
Table 2 Preexisting associated systemic diseases

\begin{tabular}{lll}
\hline Systemic disease & CRVO (n=33) & BRVO (n=55) \\
\hline Systemic hypertension & $19(57.58 \%)$ & $30(54.55 \%)$ \\
Diabetes mellitus & $10(30.30 \%)$ & $9(16.36 \%)$ \\
Hyperlipidemia & $3(9.09 \%)$ & $4(7.27 \%)$ \\
Systemic thrombosis & $1(3.03 \%)$ & $7(12.73 \%)$ \\
\hline
\end{tabular}

Abbreviations: BRVO, branch retinal vein occlusion; CRVO, central retinal vein occlusion.

The presence of associated systemic diseases (systemic hypertension, diabetes, hyperlipidemia or systemic thrombosis) in these patients is shown in Table 2.

In this study, 33 (37.50\%) eyes were with CRVO and 55 with BRVO (Figure 1). Furthermore, 65 eyes (73.86\%) had clinically significant improvement of BCVA $(>0.3 \log$ MAR units), of which 46 were with BRVO and 19 were with CRVO. Moreover, 23 eyes (26.14\%) - 9 with BRVO and 14 with CRVO - had poor response to treatment (ie, improvement of BCVA $<0.3 \log$ MAR units).

There was significant improvement $(P=0.001)$ of the mean BCVA in patients with CRVO from $1.2 \pm 0.95 \log$ MAR units ( $0.065 \pm 0.108$ Snellen decimal units) before treatment to $0.75 \pm 0.6 \log$ MAR units $(0.175 \pm 0.257$ Snellen decimal units) at the 1-year follow-up. Significant improvement of mean BCVA $(P<0.001)$ was also found in the BRVO group, from baseline VA of $0.71 \pm 0.75 \log$ MAR units $(0.198 \pm 0.176$ Snellen decimal units) to $0.28 \pm 0.5 \operatorname{logMAR}$ units $(0.519 \pm 0.317$ Snellen decimal units) at 1 year post-treatment (Figure 2).

The CMT significantly decreased $(P<0.001)$ in cases with CRVO, from $852.21 \pm 298.20 \mu \mathrm{m}$ at baseline to $317.67 \pm 207.13 \mu \mathrm{m} 1$ year after treatment. The same was true also for the cases with BRVO, where CMT decreased from $597.95 \pm 185.63 \mu \mathrm{m}$ before injection to $294.73 \pm 113.95 \mu \mathrm{m}$ after 1 year (Figure 3).

In Figures 4 and 5, we present the OCT findings of a case of BRVO and a case of CRVO, respectively, after one injection of bevacizumab, at baseline and at 1-year follow-up.

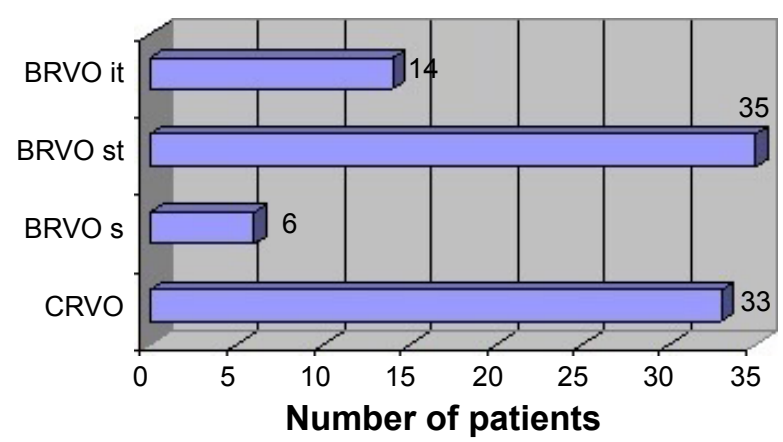

Figure I Distribution of patients by type of RVO.

Abbreviations: BRVO it, inferotemporal branch RVO; BRVO st, superotemporal branch RVO; BRVO s, superior hemi-RVO; CRVO, central RVO; RVO, retinal vein occlusion.

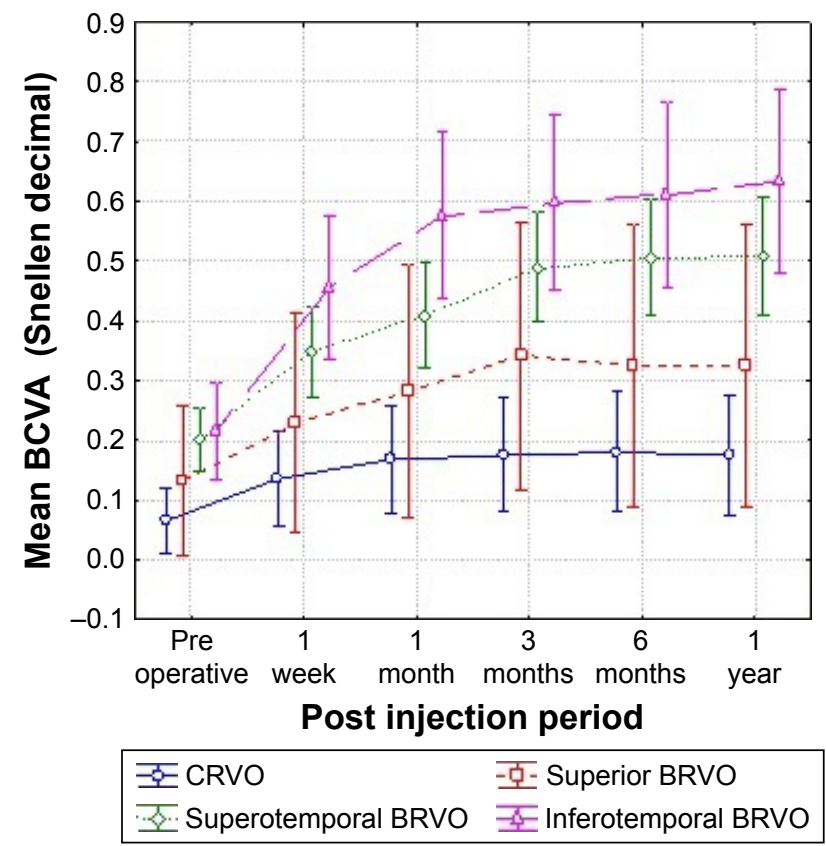

Figure 2 Changes in visual acuity in RVO.

Abbreviations: BCVA, best-corrected visual acuity; BRVO, branch retinal vein occlusion; CRVO, central retinal vein occlusion.

Regarding the IOP, no significant difference was found $(P>0.05)$ at the beginning and at the end of the follow-up period in either CRVO or BRVO.

In 52 eyes, the FFA confirmed the existence of ischemic zones on the retina, after which LPC was conducted panretinal photocoagulation (PRP) in 25 out of 33 eyes with CRVO (75.8\%) and sectoral LPC in 27 out of 55 eyes with BRVO (49.1\%). Despite this fact, concerning the

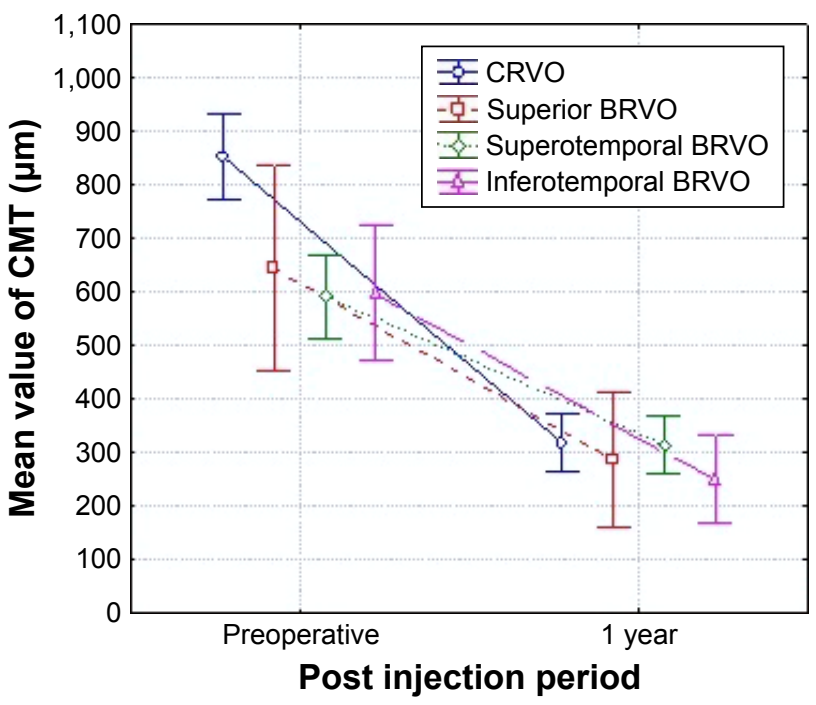

Figure 3 Changes in CMT in RVO.

Abbreviations: BRVO, branch RVO; CMT, central macular thickness; CRVO, central RVO; RVO, retinal vein occlusion. 

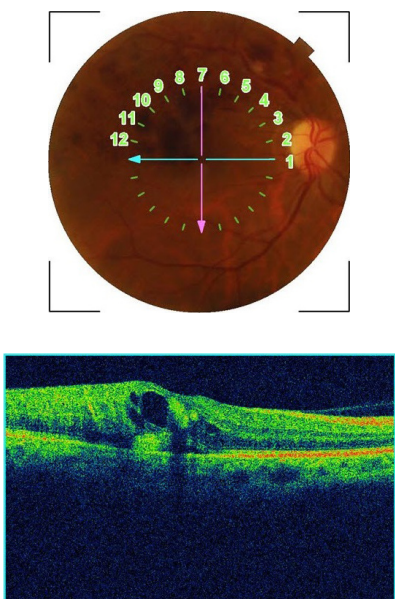

$\mathrm{VA}=0.8 \log \mathrm{MAR}$ (baseline)

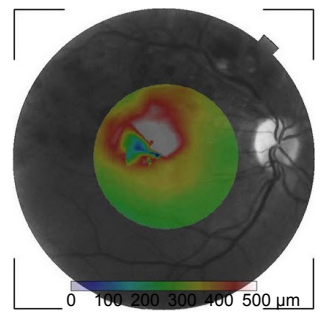

Retinal thickness ILM - RPE ( $\mu \mathrm{m})$

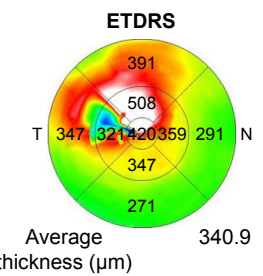

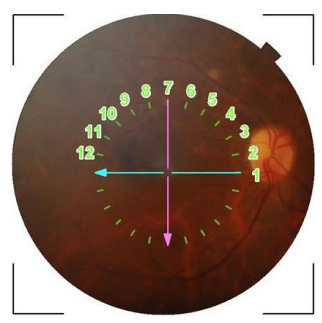

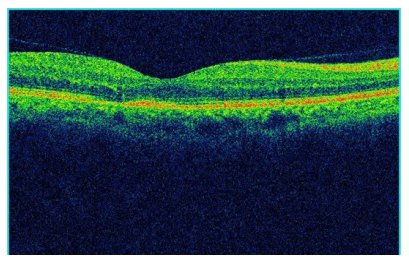

VA $=0.2$ logMAR (1 year, 1 injection)

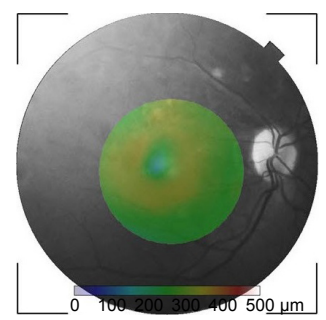

Retinal thickness ILM - RPE $(\mu \mathrm{m})$

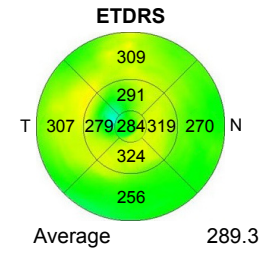

thickness $(\mu \mathrm{m})$

Figure 4 OCT images of a case of BRVO (superotemporal) at baseline and after I-year follow-up with one injection of bevacizumab.

Abbreviations: BRVO, branch retinal vein occlusion; OCT, optical coherence tomography; VA, visual acuity; ILM-RPE, internal limiting membrane to retinal pigment epithelium; ETDRS, Early Treatment Diabetic Retinopathy Study map.

complications resulting from the disease, five patients developed vitreal hemorrhage (four [5.6\%] with CRVO and one [1.8\%] with BRVO), nine patients were diagnosed and treated for glaucoma (six [10.2\%] with CRVO and three [5.4\%] with BRVO).

We also followed a group of 33 patients who refused any treatment for RVO ( 15 eyes with CRVO and 18 eyes with BRVO). The mean pretreatment BCVA for this group was $1.49 \pm 1.22$ for CRVO and $0.53 \pm 0.59$ for BRVO. After 1 year, although there was significant decrease in CMT in this group $(639.80 \pm 386.81 \mu \mathrm{m}$ down to $419.73 \pm 333.59 \mu \mathrm{m}$ in CRVO and $511.00 \pm 187.41 \mu \mathrm{m}$ down to $354.00 \pm 187.74 \mu \mathrm{m}$ in BRVO); the mean BCVA and IOP had no significant difference compared to those of the first examination. As expected, the percentage of complications in this group was much higher after 1 year of follow-up. In the CRVO group, vitreal hemorrhage developed in four (26.7\%) eyes and secondary glaucoma in six (40\%). In the BRVO group, vitreal hemorrhage developed in four (22.2\%) eyes and secondary glaucoma in two eyes (11.1\%).

In comparison, after 1 year, the mean BCVA was significantly higher $(P<0.01)$ in the treated group than in the control group, for both CRVO and BRVO. There was no significant difference in CMT or IOP at the end of the follow-up period between the treated and control groups.

We also performed a multiple regression analysis in which BCVA at 12 months was considered a dependent variable and the influence of the following risk factors as
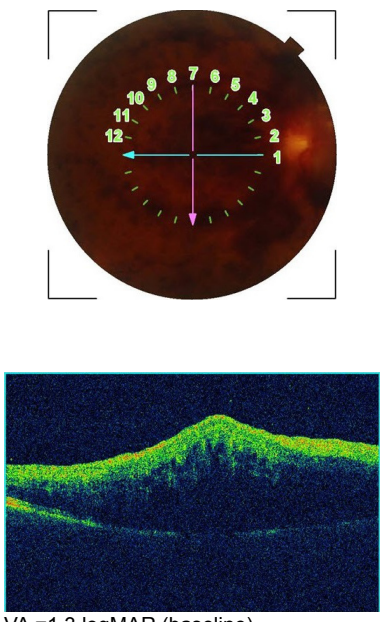

$\mathrm{VA}=1.3 \log M A R$ (baseline)

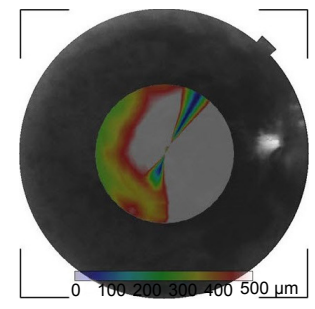

Retinal thickness ILM - RPE $(\mu \mathrm{m})$

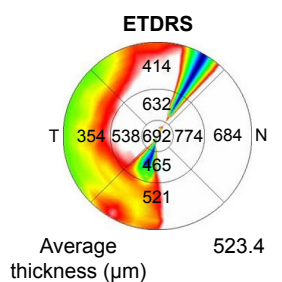

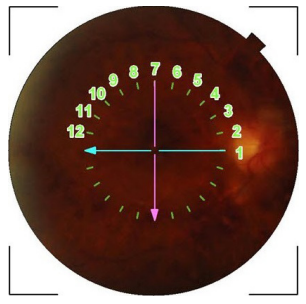

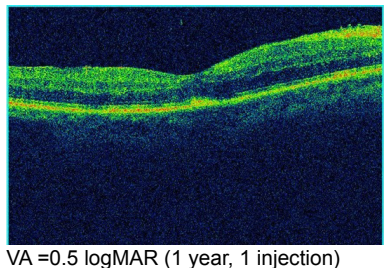

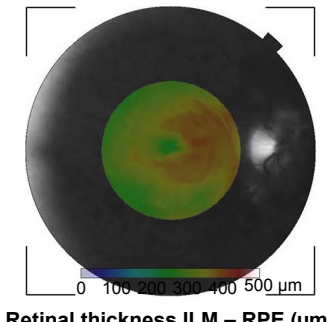

Retinal thickness ILM - RPE ( $\mu \mathrm{m})$

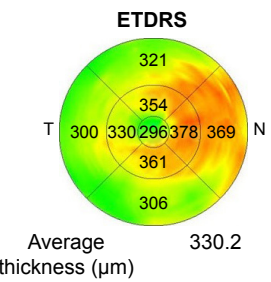

Figure 5 OCT images of a case of CRVO at baseline and after I-year follow-up with one injection of bevacizumab.

Abbreviations: CRVO, central retinal vein occlusion; OCT, optical coherence tomography; VA, visual acuity; ILM-RPE, internal limiting membrane to retinal pigment epithelium; ETDRS, Early Treatment Diabetic Retinopathy Study map. 
Table 3 Multiple regression analysis - influence of risk factors on BCVA in BRVO at I year

\begin{tabular}{lllllll}
\hline BCVA (BRVO) and risk factors & Beta & SE of beta & B & SE of B & $t(27)$ & -2.192 \\
\hline Duration of disease & -0.303 & 0.138 & -0.010 & 0.005 & $0.03 *$ \\
HTA & 0.055 & 0.140 & 0.035 & 0.088 & 0.393 & 0.70 \\
DM & -0.045 & 0.135 & -0.039 & 0.115 & -0.336 & 0.74 \\
Hyperlipidemia & 0.074 & 0.136 & 0.090 & 0.165 & 0.546 & 0.59 \\
Systemic thrombosis & 0.081 & 0.137 & 0.077 & 0.129 & 0.596 & 0.55 \\
\hline
\end{tabular}

Note: *Shorter duration of disease in BRVO preinjection was associated with better visual acuity after 12 months of the initial injection ( $P=0.03$, multiple regression analysis). Abbreviations: BCVA, best-corrected visual acuity; BRVO, branch retinal vein occlusion; DM, diabetes mellitus; HTA, arterial hypertension; SE, standard error.

independent variables: duration of the disease, hypertension, diabetes mellitus, hyperlipidemia and systemic thrombosis. We found that longer duration of the disease significantly decreases $(P<0.05)$ the BCVA at 12 months in BRVO (Table 3). No significant correlations were found for BCVA in CRVO. Similar analysis was done for CMT at 12 months, which showed that patients with CRVO and systemic thrombosis have significantly higher CMT $(P<0.001)$ than patients who do not have this risk factor (Table 4). In addition, no significant correlations were found in the BRVO group.

With regard to ocular or systemic complications and side effects associated with intravitreal administration of bevacizumab (endophthalmitis, uveitis, occurrence or progression of cataract, prolonged elevation of IOP, vascular events and so on), no such events were recorded during the monitoring period of the treated eyes.

\section{Discussion}

Therapies that were investigated in the treatment of RVO but failed to achieve the desired results, or have been associated with adverse complications, include laser-induced chorioretinal-venous anastomosis, isovolumic hemodilution therapy, oral pentoxifylline, hyperbaric oxygen therapy, radial optic neurotomy and so on. ${ }^{17-20}$ The comparative efficacy of vitrectomy, tissue plasminogen activator (tPA) and bevacizumab was assessed by Kumagai et $a l,{ }^{21}$ and the visual outcome at 12 months was similar for all three groups. While plasmin and vitrectomy seem to show promising results, ${ }^{21-23}$ they require further validation before being accepted as a routine management modality.
Intravitreal injection of triamcinolone acetonide was used in the treatment of RVO with different success rates. ${ }^{24}$ Although it showed promising results, it was associated with side effects such as increased IOP and cataract formation.

Since the first report on the efficacy of intravitreal bevacizumab in a patient with ME secondary to CRVO in 2005, ${ }^{25}$ several studies have been conducted that show a decrease in ME and improvement of VA after multiple injections of bevacizumab, but variability in the frequency of doses and outcomes hinder the possibility of comparability of these studies. ${ }^{26-29}$

Hikichi et $\mathrm{a}^{27}$ reported significant improvement of BCVA in BRVO from $0.64 \pm 0.24 \log$ MAR units to $0.33 \pm 0.21$ $\operatorname{logMAR}$ units after 1 year, with average 2.6 injections of bevacizumab in this period. This is comparable to our results wherein BCVA improved from 0.71 $\pm 0.75 \log$ MAR units to $0.28 \pm 0.5 \log$ MAR units in the eyes with BRVO and an average of 1.98 injections. The improvement of CMT reported in their study (from $572 \pm 134 \mu \mathrm{m}$ at baseline to $211 \pm 45 \mu \mathrm{m}$ at 1 year) was slightly better than our results $(597 \pm 185 \mu \mathrm{m}$ at preinjection time point to $294 \pm 113 \mu \mathrm{m}$ after 1 year), probably due to the lower number of injections. Therefore, we consider that the decision for reinjection should be made on the basis of not only the macular thickness but also VA follow-up.

Epstein et $\mathrm{al}^{29}$ applied bevacizumab injections every 6 weeks for 12 months in eyes with CRVO. They reported BCVA improvement by 16.0 letters and mean decrease in CMT of $435 \mu \mathrm{m}$ at 12 months. In our study, we achieved slightly better results (BCVA improvement of 20.0 letters and CMT decrease of $534 \mu \mathrm{m}$ ) with fewer injections. The possible

Table 4 Multiple regression analysis - influence of risk factors on CMT in CRVO at I year

\begin{tabular}{lllllll}
\hline CMT (CRVO) and risk factors & Beta & SE of beta & B & SE of B & t(27) & P-level \\
\hline Duration of disease & -0.12 & 0.16 & -5.28 & 7.06 & -0.75 & 0.46 \\
HTA & -0.12 & 0.14 & -48.34 & 57.61 & -0.84 & 0.41 \\
DM & 0.04 & 0.15 & 15.80 & 68.36 & 0.23 & 0.82 \\
Hyperlipidemia & 0.09 & 0.13 & 61.99 & 94.51 & 0.66 & 0.52 \\
Systemic thrombosis & 0.71 & 0.15 & 847.98 & 175.07 & 4.84 & $0.00 I^{*}$ \\
\hline
\end{tabular}

Note: *Presence of systemic thrombosis in CRVO patients preinjection was associated with worse CMT results after 12 months of the initial injection compared to patients who did not have this risk factor ( $P=0.00$ I, multiple regression analysis).

Abbreviations: CRVO, central retinal vein occlusion; CMT, central macular thickness; DM, diabetes mellitus; HTA, arterial hypertension; SE, standard error. 
explanation can be that we performed early PRP (usually after the first injection) in a large percentage of eyes with CRVO (75.8\%). Campochiaro et $\mathrm{al}^{30}$ found no significant improvement in BCVA or CMT in eyes with RVO treated with ranibizumab and PRP, but in their study, the PRP was conducted late, after 24 weeks of anti-VEGF treatment.

One recent study conducted in the UK reported the outcome of bevacizumab treatment on RVO-induced ME with PRN regimen in real-world setting. ${ }^{31}$ Although the anatomical result was favorable (CMT significantly decreased after 1 year), the functional outcome was worse than in our study, ie, they found no significant improvement of BCVA after 12 months of follow-up, whereas in our study, BCVA was significantly increased after 1 year in both CRVO and BRVO groups. This is probably due to the fact that their study included high number of cases with chronic edema (persisting edema of $>12$ months' duration), which were previously treated with laser or intravitreal steroid injections.

Several large multicentric, randomized, placebo-controlled Phase III trials have evaluated the efficacy of ranibizumab in acute ME after RVO and confirmed the safety and efficacy of this medication. In two large studies $\left(\mathrm{BRAVO}^{32}\right.$ and CRUISE $^{33}$ ), six intraocular injections at monthly intervals of $0.3 \mathrm{mg}$ or $0.5 \mathrm{mg}$ of ranibizumab were applied to eyes with BRVO and CRVO, respectively, followed by PRN in the next 6 months. At month 12, the mean gain in the Early Treatment Diabetic Retinopathy Study (ETDRS) letter score in the $0.5 \mathrm{mg}$ group was 18.3 for BRVO and 13.9 for CRVO, with an average of 8.7 injections. Our results with bevacizumab were comparable to these results, but with less number of injections.

Another randomized trial (MARVEL) ${ }^{34}$ compared the effects of bevacizumab and ranibizumab in BRVO-associated $\mathrm{ME}$, with intravitreal injections administered on a PRN basis. After 6 months, both groups had comparable BCVA, CMT and mean number of injections (3.2 for ranibizumab and 3.0 for bevacizumab). We consider that due to the nature of $\mathrm{RVO}$ as a one-time incident, as opposed to chronic diseases, such as macular degeneration or diabetic maculopathy, the monthly anti-VEGF injections applied in these diseases are not always required in the cases of RVO.

In our study, the use of intravitreal bevacizumab led to sustained improvement of VA, as well as reduction of ME, over a period of 1 year. Significantly, better results were achieved in patients with BRVO versus those with CRVO. In six (6.8\%) eyes, BCVA remained the same or worsened, mostly due to complications of the disease. Although the applied retinal laser treatment (PRP or sectoral, but not macular, grid laser) can have indirect effects on the ME, we considered that the benefits of this treatment in prevention of late complications much outweigh the possible influence on the results.

The study was not designed to evaluate the possibility of spontaneous resolution of ME in BRVO. However, the possibility of spontaneous improvement should not exclude early treatment of eyes with ME in BRVO. That fact is supported by data from the SCORE study, ${ }^{35}$ which proved that the short duration of ME before treatment was associated with greater improvement in VA after treatment. In our study, multiple regression analysis also showed that longer duration of the disease significantly decreases $(P<0.05)$ the BCVA at 12 months in BRVO.

Regarding the systemic safety of bevacizumab, although the medication is used off label, to this date, the studies conducted to compare its safety relative to other approved medications (ranibizumab, aflibercept) did not demonstrate increased systemic adverse events for either of them. ${ }^{36,37}$ Moreover, in our study, no systemic vascular events or other drug-related incidents occurred in the follow-up period.

Limitations of this study include the lack of randomization and the use of Snellen decimal VA charts (with conversion to $\log$ MAR). This study represents our initial results and experiences in the use of intravitreal antiangiogenic agents in RVOs as in the Republic of Macedonia, the history of use of these agents in ophthalmology is relatively short (only 5 years). Moreover, considering the fact that this treatment is not covered by the countries' health insurance, the cost of the therapy for the patient tends to be very high, if multiple injections are required. Many times, in reallife setting, the low-dose anti-VEGF treatment for ME is the only alternative to conservative treatment. It will take further clinical studies with an appropriate design and a larger series of patients with long-term monitoring in order to evaluate the efficacy and safety of this treatment and to obtain definitive results.

\section{Conclusion}

Antiangiogenic agents have revolutionized the approach to treatment of ME in RVO. With this study, we confirmed the efficacy of intravitreal bevacizumab for RVO-induced ME with regard to improvement of both BCVA and CMT, as well as in prevention of disease-related complication. Even low-frequency bevacizumab treatment is justified, especially if other anti-VEGF agents are unavailable. Long-term studies are needed in order to evaluate the continuity of anatomical and functional recovery. 


\section{Disclosure}

The authors report no conflicts of interest in this work.

\section{References}

1. Hayreh SS. Prevalent misconceptions about acute retinal vascular occlusive disorders. Prog Retin Eye Res. 2005;24(4):493-519.

2. Wong TY, Larsen EK, Klein R, et al. Cardiovascular risk factors for retinal vein occlusion and arteriolar emboli: the Atherosclerosis Risk in Communities \& Cardiovascular Health studies. Ophthalmology. 2005;112(4):540-547.

3. Mitchell P, Smith W, Chang A. Prevalence and associations of retinal vein occlusion in Australia: the Blue Mountains Eye Study. Arch Ophthalmol. 1996;114(10):1243-1247.

4. Klein R, Klein BE, Moss SE, Meuer SM. The epidemiology of retinal vein occlusion: the Beaver Dam Eye Study. Trans Am Ophthalmol Soc. 2000;98:133-141.

5. Klein R, Moss SE, Meuer SM, Klein BE. The 15-year cumulative incidence of retinal vein occlusion: the Beaver Dam Eye Study. Arch Ophthalmol. 2008;126(4):513-518.

6. Cugati S, Wang JJ, Rochtchina E, Mitchell P. Ten-year incidence of retinal vein occlusion in an older population: the Blue Mountains Eye Study. Arch Ophthalmol. 2006;124(5):726-732.

7. The Royal College of Ophthalmologists [homepage on the Internet]. The Royal College of Ophthalmologists Clinical Guidelines: Retinal Vein Occlusion (RVO) Guidelines; 2015. Available from: http://www. rcophth.ac.uk. Accessed May 15, 2017.

8. The Central Vein Occlusion Study Group: evaluation of grid pattern photocoagulation for macular edema in central vein occlusion. $O p h-$ thalmology. 1995;102:1425-1433.

9. The Branch Vein Occlusion Study Group: argon laser photocoagulation for macula edema in branch vein occlusion. Am J Ophthalmol. 1984;98:271-282.

10. Scott IU, Ip MS, VanVeldhuisen PC, et al. SCORE Study Research Group A randomized trial comparing the efficacy and safety of intravitreal triamcinolone with standard care to treat vision loss associated with macular Edema secondary to branch retinal vein occlusion: the Standard Care vs Corticosteroid for Retinal Vein Occlusion (SCORE) study report 6. Arch Ophthalmol. 2009;127(9):1115-1128.

11. Ip MS, Scott IU, VanVeldhuisen PC, et al. SCORE Study Research Group A randomized trial comparing the efficacy and safety of intravitreal triamcinolone with observation to treat vision loss associated with macular edema secondary to central retinal vein occlusion: the Standard Care vs Corticosteroid for Retinal Vein Occlusion (SCORE) study report 5. Arch Ophthalmol. 2009;127(9):1101-1114.

12. Aiello LP, Avery RL, Arrigg PG, et al. Vascular endothelial growth factor in ocular fluid of patients with diabetic retinopathy and other retinal disorders. N Engl J Med. 1994;331(22):1480-1487.

13. Noma H, Funatsu H, Mimura T, et al. Increase of vascular endothelial growth factor and interleukin-6 in the aqueous humour of patients with macular edema and central retinal vein occlusion. Acta Ophthalmol. 2010;88(6):646-651.

14. Campochiaro PA. Anti-vascular endothelial growth factor treatment for retinal vein occlusions. Ophthalmologica. 2012;227(suppl 1):30-35. doi: $10.1159 / 000337157$.

15. Mitry D, Bunce C, Charteris D. Anti-vascular endothelial growth factor for macular oedema secondary to branch retinal vein occlusion Cochrane Database Syst Rev. 2013;1:CD009510.

16. Braithwaite T, Nanji AA, Lindsley K, Greenberg PB. Anti-vascular endothelial growth factor for macular oedema secondary to central retinal vein occlusion. Cochrane Database Syst Rev. 2014;5: CD007325.

17. Höh AE, Schaal KB, Dithmar S. Central and branch retinal vein occlusion: current strategies for treatment in Germany, Austria and Switzerland. Ophthalmologe. 2007;104(4):290-294.

18. Park CH, Scott AW, Fekrat S. Effect of oral pentoxifylline on cystoid macular edema associated with central retinal vein occlusion. Retina. 2007;27(8):1020-1025.
19. Wright JK, Franklin B, Zant E. Clinical case report: treatment of a central retinal vein occlusion with hyperbaric oxygen. Undersea Hyperb Med. 2007;34(5):315-319.

20. Arevalo JF, Garcia RA, Wu L, et al. Radial optic neurotomy for central retinal vein occlusion: results of the Pan-American Collaborative Retina study group (PACORES). Retina. 2008;28(8):1044-1052.

21. Kumagai K, Ogino N, Furukawa M, Larson E. Three treatments for macular edema because of branch retinal vein occlusion: intravitreous bevacizumab or tissue plasminogen activator, and vitrectomy. Retina. 2012;32(3):520-529.

22. Park DH, Kim IT. Long-term effects of vitrectomy and internal limiting membrane peeling for macular edema secondary to central retinal vein occlusion and hemiretinal vein occlusion. Retina. 2010;30(1):117-124.

23. Weiss JN, Bynoe LA. Injection of tissue plasminogen activator into a branch retinal vein in eyes with central retinal vein occlusion. Ophthalmology. 2001;108(12):2249-2257.

24. Gewaily D, Greenberg PB. Intravitreal steroids versus observation for macular edema secondary to central retinal vein occlusion. Cochrane Database Syst Rev. 2009;1:CD007324.

25. Rosenfeld PJ, Fung AE, Puliafito CA. Optical coherence tomography findings after an intravitreal injection of bevacizumab $\left(\right.$ Avastin $\left.^{\circledR}\right)$ for macular edema from central retinal vein occlusion. Ophthalmic Surg Lasers Imaging. 2005;36(4):336-339.

26. Badalà $F$. The treatment of branch retinal vein occlusion with bevacizumab. Curr Opin Ophthalmol. 2008;19(3):234-238.

27. Hikichi T, Higuchi M, Matsushita T, et al. Two-year outcomes of intravitreal bevacizumab therapy for macular oedema secondary to branch retinal vein occlusion. Br J Ophthalmol. 2014;98(2):195-199.

28. Gregori NZ, Gaitan J, Rosenfeld PJ, et al. Long-term safety and efficacy of intravitreal bevacizumab (Avastin) for the management of central retinal vein occlusion. Retina. 2008;28(9):1325-1337.

29. Epstein DL, Algvere PV, von Wendt G, Seregard S, Kvanta A. Benefit from bevacizumab for macular edema in central retinal vein occlusion: twelve-month results of a prospective, randomized study. Ophthalmology. 2012;119(12):2587-2591.

30. Campochiaro PA, Hafiz G, Mir TA, et al. Scatter photocoagulation does not reduce macular edema or treatment burden in patients with retinal vein occlusion: the RELATE trial. Ophthalmology. 2015; 122(7):1426-1437.

31. Lip PL, Malick H, Damer K, et al. One-year outcome of bevacizumab therapy for chronic macular edema in central and branch retinal vein occlusions in real-world clinical practice in the UK. Clin Ophthalmol. 2015;9:1779-1784.

32. Brown DM, Campochiaro PA, Bhisitkul RB, et al. Sustained benefits from ranibizumab for macular edema following branch retinal vein occlusion: 12-month outcomes of a phase III study. Ophthalmology. 2011;118(8):1594-1602.

33. Campochiaro PA, Brown DM, Awh CC, et al. Sustained benefits from ranibizumab for macular edema following central retinal vein occlusion: twelve-month outcomes of a phase III study. Ophthalmology. 2011;118(10):2041-2049.

34. Narayanan R, Panchal B, Das T, et al. A randomised, double-masked, controlled study of the efficacy and safety of intravitreal bevacizumab versus ranibizumab in the treatment of macular oedema due to branch retinal vein occlusion: MARVEL Report No. 1. Br J Ophthalmol. 2015;99(7):954-959.

35. SCORE Study Research Group. A randomized trial comparing the efficacy and safety of intravitreal triamcinolone with standard care to treat vision loss associated with macular Edema secondary to branch retinal vein occlusion: the Standard Care vs Corticosteroid for Retinal Vein Occlusion (SCORE) study report 6. Arch Ophthalmol. 2009;127(9):1115-1128.

36. Martin DF, Maguire MG, Ying GS, et al. Ranibizumab and bevacizumab for neovascular age-related macular degeneration. $N$ Engl $J$ Med. 2011;364(20):1897-1908.

37. Diabetic Retinopathy Clinical Research Network, Wells JA, Glassman AR, et al. Aflibercept, bevacizumab, or ranibizumab for diabetic macular edema. $N$ Engl J Med. 2015;372(13):1193-1203. 


\section{Publish your work in this journal}

Clinical Ophthalmology is an international, peer-reviewed journal covering all subspecialties within ophthalmology. Key topics include: Optometry; Visual science; Pharmacology and drug therapy in eye diseases; Basic Sciences; Primary and Secondary eye care; Patient Safety and Quality of Care Improvements. This journal is indexed on

Submit your manuscript here: http://www.dovepress.com/clinical-ophthalmology-journal
PubMed Central and CAS, and is the official journal of The Society of Clinical Ophthalmology (SCO). The manuscript management system is completely online and includes a very quick and fair peer-review system, which is all easy to use. Visit http://www.dovepress.com/ testimonials.php to read real quotes from published authors. 